\title{
Compliance with consolidation (group) accounting standards the vertical adjustment issue: a survey of Swedish...
}

Article in J for Global Business Advancement · January 2007

DOI: 10.1504/JGBA.2007.012548

CITATIONS

3

3 authors:

Arne Fagerström

University of Gävle

29 PUBLICATIONS 11 CITATIONS

SEE PROFILE

\section{Gary Cunningham}

University of Gävle

28 PUBLICATIONS 235 CITATIONS

SEE PROFILE
READS

52
Lars G. Hassel

Umeå University

32 PUBLICATIONS 395 CITATIONS

SEE PROFILE

Some of the authors of this publication are also working on these related projects: 


\title{
Compliance with consolidation (group) accounting standards - the vertical adjustment issue: a survey of Swedish multinationals
}

\author{
Arne Fagerström* \\ Linköping University, SE-583 81 Linköping, Sweden \\ E-mail: arnfa@eki.liu.se \\ *Corresponding author \\ Lars G. Hassel \\ Åbo Akademi University, FIN-20500 Turku, Finland \\ E-mail: Lhassel@abo.fi
}

\section{Gary M. Cunningham}

Bilkent University, Faculty of Management, TR - 06800 Bilkent,

Ankara, Turkey

E-mail: g_m_cunningham@yahoo.com

\begin{abstract}
Previous research into consolidated financial reporting of multinational companies has focused on horizontal adjustments, adjustments at the headquarters level to comply with accounting standards of the country where a stock exchange listing is made, e.g. US GAAP, or IFRS. An equally, if not more, important issue is vertical adjustments made by foreign subsidiaries when information is transmitted to the headquarters for consolidation. This study surveys all Swedish multinational companies listed on the Stockholm Stock Exchange, firstly in the early 1990s and again some 10 years later to determine whether vertical adjustments were made as an indicator of compliance with Swedish accounting standards. The results indicate that while most Swedish multinational companies made vertical adjustments, the large number that did not indicates a potentially high degree of non-compliance with accounting standards. In all cases, though, the companies claimed they had complied and their auditors concurred.
\end{abstract}

Keywords: accounting standard compliance; consolidated financial reporting; group accounting; multinationals; subsidiary reporting; vertical adjustments.

Reference to this paper should be made as follows: Fagerström, A., Hassel, L.G. and Cunningham, G.M. (2007) 'Compliance with consolidation (group) accounting standards - the vertical adjustment issue: a survey of Swedish multinationals', J. Global Business Advancement, Vol. 1, No. 1, pp.37-48.

Biographical notes: Arne Fagerström is an Accounting Professor at the Management School, Linköping University in Sweden. He has held previous academic appointments and shorter-term teaching and research presentations in many countries. He also has held previous assignments in leading positions in Swedish multinationals. He holds a DrSc (Econ. \& Bus.) in Accounting from Åbo Akademi University. 
Lars G. Hassel is Professor of Accounting at Åbo Akademi University in Turku, Finland and a Visiting Professor at Umeå School of Business, Umeå, Sweden. He recently received an Honorary Professorship at Khabarovsk State Academy of Economics and Law in Russia. He holds a DrSc (Econ. \& Bus.) degree in Accounting from Åbo Akademi University. He has had academic appointments in Estonia, New Zealand, Malaysia and France and he has been a Fulbright scholar in the US. His research and other scholarly writings have appeared in leading academic journals internationally.

Dr Gary M. Cunningham is an Accounting Professor at Bilkent University in Ankara, Turkey. He has held previous academic appointments in Lebanon, Spain, Germany, Australia and the US, and he has had many shorter-term teaching and research presentations in various countries. He had a $\mathrm{PhD}$ in accounting from the University of Texas at Austin. His research an other scholarly writings have appeared in leading academic journals internationally.

\section{Introduction}

Companies' compliance with accounting standards has become a major issue, especially for multinational companies. Two major reasons are:

- recent accounting and reporting scandals involving non-compliance with standards in the USA and in Europe, often involving multinationals

- the requirement of the European Union (EU) for all publicly listed companies, most of which are multinationals, to comply with International Financial Reporting Standards (IFRS) ${ }^{1}$ beginning in 2005 and the related issue of enforcement mechanisms to assure compliance with IFRS.

The issue is especially important considering the findings of Street and Gray (2002) and Street et al. (1999) that companies do not actually fully comply with IFRS, even though they say they do and auditors' concurred that the statements comply with IFRS. These two studies focused on what we call the horizontal adjustment issue, the adjustment and preparation of financial reports at the headquarters level. An equally significant compliance issue for multinational companies is what we call the vertical adjustment issue, adjustments made to local subsidiary financial reports to comply with the accounting standards of the parent company for consolidated financial reporting.

This study examines vertical adjustments, because the greatest opportunity for non-compliance is present at this level. In this study, we survey all companies on the Stockholm Stock Exchange that have international subsidiaries in the early 1990s and again some 10 years later, and examine their annual reports. The surveys determined whether the companies made vertical adjustments as an indication of compliance with Swedish accounting standards and the factors that affected decisions to make vertical adjustments. The lack of vertical adjustments per se does not prove non-compliance with accounting standards. Considering the nature of Swedish multinationals and their business, the lack of vertical adjustments is a strong indicator of non-compliance. In the next section, we develop the background about consolidation accounting, especially vertical adjustments, with a focus on Swedish 
accounting standards. We then present the results. A final concluding discussion presents implications for continued research.

\section{Consolidated financial reporting}

Multinational corporations face accounting diversity among countries when they consolidate their financial reports, because subsidiaries in different countries are subject to differing accounting standards. When Swedish multinationals consolidate their financial reports, they must eliminate this diversity in order to present consolidated financial statements for the group as a whole in accordance with Swedish accounting principles. The question is whether subsidiaries adjust financial information presented to the parent company to conform with Swedish accounting standards before it is submitted to the headquarters - vertical adjustments. Failure to make vertical adjustments does not by itself prove non-compliance with Swedish accounting standards. It is always possible that there are no differences between local countries' accounting standards and those of the Swedish parent. Because of the nature of multinational business and the well-known differences among countries, though, it is highly unlikely that differences are not present. It is also possible that vertical adjustments would be immaterial. Again, because of the nature of multinational business activity and the well-known nature of the differences, failure to make adjustments on grounds of materiality is unlikely. The survey did assess materiality issues, however. This study, therefore, is based on the premise that a failure to make vertical adjustments is a strong indicator of non-compliance with Swedish accounting standards. By contrast, horizontal adjustments occur when a company adjusts its entire set of consolidated financial reports to comply with the accounting standards of another country, or with IFRS, as when a Swedish multinational presents information to the NY Stock Exchange in accordance with US generally accepted accounting standards (GAAP). Vertical and horizontal adjustments are illustrated in Figure 1. A third type of subsidiary reporting, also shown in Figure 1, is possible when a subsidiary reports to the parent company following the accounting standards of a foreign stock exchange, as for example when a US Subsidiary of a Swedish multinational reports to the parent following US GAAP for consolidated financial reports prepared for presentation in the USA. This third type of reporting is not considered further in this paper, but is a potential topic for future research.

Swedish companies were among the first to establish foreign subsidiaries and thus they have many years experience in dealing with accounting diversity among countries. Swedish multinationals are also experienced in producing financial reports for major foreign stock exchanges including the important New York and London Stock Exchanges.

At the time of the first survey in the early 1990s, Swedish financial reporting was governed by the accounting act of 1975 . This act required consolidated financial reporting as a complement to parent company financial statements, with the consolidated amounts being all presented based on Swedish accounting regulations. Traditionally, Swedish financial reporting, including the accounting act of 1975, has closely followed income tax legislation. In 1989, the private-sector accounting standards setting board was created in Sweden. In 1990 this board issued standards for consolidated 
financial reporting. The survey made in the early 1990s was designed to determine the extent of compliance with the accounting act of 1975 and the standard adopted in 1990 .

During the mid-1990s, Swedish financial reporting underwent several changes. When Sweden joined the EU, it was required to adopt EU directives. In addition, changes were made to the Swedish accounting regulations and the standards-setting board issued several standards. These changes did not affect the basic requirement of consolidated financial reporting, but did move Swedish financial reporting away from legalistic tax-linked accounting to the 'true and fair view'. The changes also required use of IFRS. The legislation of the mid-1990s specifically emphasised the need for compliance with Swedish accounting standards when subsidiaries are consolidated:

"Group accounting should be carried out with uniform accounting principles. The starting point is that group accounting principles should be in conformity with the accounting principles used in the annual report of the parent company. The subsidiary reports that constitute the basis in the consolidated accounts could, if necessary, be adjusted to conform with the group accounting principles. In rare exceptions, when adjustments cannot be made, disclosure of the reasons for deviation from a standard must be disclosed in the report." RR 1:96, item 8 , translated.

Figure 1 Vertical and horizontal adjustments in multinational group reporting

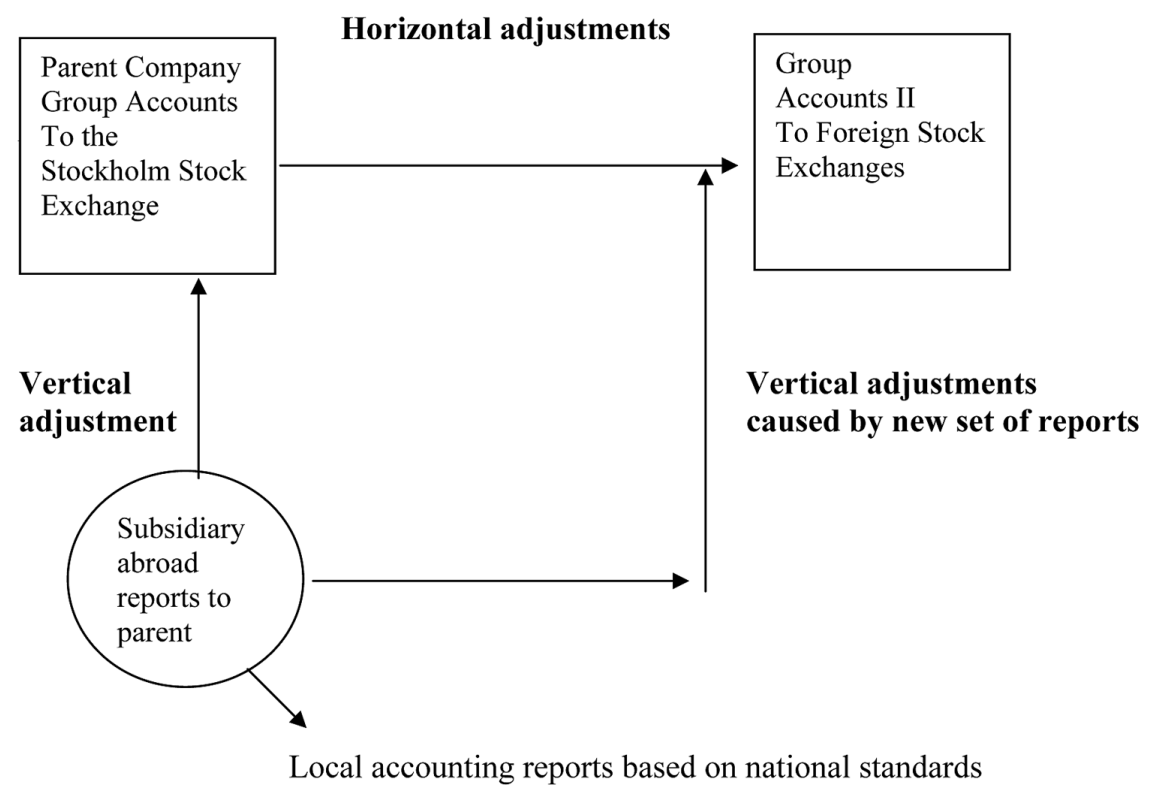


This study deals with two main research questions:

- Do Swedish groups make vertical adjustments to their locally prepared financial statements of subsidiaries in the consolidation process? As indicated above, failure to make such adjustments is a strong indicator of non-compliance with Swedish accounting standards and by implication non-compliance with IAS.

- What factors determine the vertical adjustments when the foreign subsidiaries are consolidated into group accounts?

\section{Research method and results}

The primary research method was a mail survey ${ }^{2}$ to all the companies on the Stockholm Stock Exchange that had foreign subsidiaries and themselves were not part of a consolidated group. This population comprised a large majority of the companies listed on the exchange. The mail survey was preceded by telephone calls to identify appropriate persons to respond to the survey and the willingness of the companies to respond. Follow-up telephone calls were made to obtain responses. Annual reports of the companies surveyed were also analysed to determine what comments and disclosures were made about consolidated financial reporting. The first survey was in the early 1990s over the period 1990 to 1992 . Another survey was made some ten years later in the period 1999-2000 to determine if there was any change in the consolidation accounting practices of the companies. Because we are surveying populations, statistical tests of significance and inference are not appropriate.

\subsection{Early 1990s survey}

The first population surveyed had 95 companies, almost $70 \%$ of the firms on the Stockholm Stock Exchange. Responses were received from 68 companies, $72 \%$ of the population. Responses to the question of whether the company made adjustments are shown in Table 1. A surprising response was that eight of the respondents, who were supposedly in the financial and accounting functions of their companies, did not know if their companies made vertical adjustments, were not familiar with the vertical adjustment process, or otherwise were unclear about their companies' activities. Therefore, the remainder of the analysis is for 60 usable responses.

Table 1 Companies making vertical adjustments for accounting differences among countries

\begin{tabular}{lcc}
\hline & Early 1990s & Late 1990s-2000 \\
\hline Made adjustments & $41(60 \%)$ & $32(74 \%)$ \\
Did not make adjustments & $19(28 \%)$ & $11(26 \%)$ \\
Unclear & $8(12 \%)$ & - \\
Total & $68(100 \%)$ & $43(100 \%)$ \\
\hline
\end{tabular}

Responses from companies making adjustments indicated that adjustments were made for such items as inventory valuation, work in progress for subsidiaries reporting on the percentage-of-completion method, provisions for bad debts, warranty provisions, 
pension liabilities and deferred income taxes. Reasons given for making adjustments include the requirement of the Swedish accounting standard and the consistency principle. The companies not making adjustments did not offer explanations. Only one company had a disclosure in its financial report, which said:

"During the consolidation of the subsidiaries into the $\mathrm{X}$ Group accounts, adjustments to the parent company accounting rules have been made."

In all cases, auditors concurred that the financial reports complied with Swedish accounting standards, even though adjustments were not made in several and companies seemingly did not comply with accounting standards for foreign currency translation (discussed shortly). Also, $53 \%$ of the companies reported that the auditors were the second most important influence on the decision to make adjustments. Therefore, the question arose as to whether there was an association between the specific auditing firm and the decision to make adjustments. We tabulated the auditing firms for each respondent and whether adjustments were made or not. The results are not shown here to avoid revealing the identity of the specific auditing firms. There was no apparent association between the specific auditing firm and the decision to make adjustments.

Several possible factors that can affect companies' decisions to make adjustments were determined by a priori analysis and discussion with companies and accounting professionals in Sweden. These were included in the questionnaire. Some of the possible factors are discussed in the following.

\subsubsection{Foreign currency translation}

The original expectation was that the method of foreign currency translation would be related to the degree of integration of the foreign subsidiaries and that the degree of integration would be associated with the adjustment process. Among other reasons, if operations of a subsidiary are integrated, then the company would be motivated to make vertical adjustments for both internal and external accounting purposes. This notion, that vertical adjustments would be associated with foreign currency translation, was based on the expectation that companies would follow proper accounting standards for foreign currency translation. In Sweden, at that time, accounting requirements specified that the current rate method be used for independent subsidiaries while a version of the temporal method should be used for integrated subsidiaries. In this survey, 40 of the 68 companies responded that they had no integrated subsidiaries, a surprising result considering that sales subsidiaries are typically integrated. All 40 of these used the current rate method. The remaining 28 reported that they had one or more integrated subsidiaries. Yet 21 of these said they used the current rate method as well. In total, $90 \%$ reported use of the current rate method. Because improper foreign currency translation methods were apparently used, it was not possible to associate foreign currency translation with the vertical adjustment process.

\subsubsection{Number of stock exchanges}

Swedish multinationals are among the largest in the world. As a result, 16 companies in the population surveyed are listed on more than one stock exchange, usually London or one of the New York exchanges. We speculate that the additional listing(s) would motivate the companies to make adjustments, especially due to the long tradition of fairness and transparency in the Anglo-Saxon countries. The results in Table 2 confirm 
our speculations, because a large majority of the companies listed on more than one exchange made vertical adjustments, while only a small majority of companies listed on only the Stockholm Stock Exchange made vertical adjustments. This result suggests that enforcement of compliance with accounting standards in Sweden was low and that companies are motivated to make adjustments primarily because of the stricter enforcement by regulators in the US and UK.

Table 2 Adjustment activity of companies by stock exchange listings

\begin{tabular}{lcccccc}
\hline & \multicolumn{2}{c}{ Early 1990s survey } & & \multicolumn{2}{c}{ Late 1990s-2000 survey } \\
\cline { 2 - 3 } & $\begin{array}{c}\text { Stockholm } \\
\text { exchange only }\end{array}$ & $\begin{array}{c}\text { Two or more } \\
\text { exchanges }\end{array}$ & & $\begin{array}{c}\text { Stockholm } \\
\text { exchange only }\end{array}$ & $\begin{array}{c}\text { Two or more } \\
\text { exchanges }\end{array}$ \\
\hline Made adjustments & $27(60 \%)$ & $14(93 \%)$ & & $20(65 \%)$ & $12(100 \%)$ \\
No adjustments & $18(40 \%)$ & $1(7 \%)$ & & $11(35 \%)$ & - \\
Total & $45(100 \%)$ & $15(100 \%)$ & & $31(100 \%)$ & $12(100 \%)$ \\
\hline
\end{tabular}

\subsubsection{Industry group}

Different types of industries have different types of transactions and different potential adjustment situations. We therefore analysed the adjustment activity by industry. The results shown in Table 3 confirm that there are substantial differences among industries. The large majority of manufacturing firms, which tend to be complex in their business activities, do make adjustments as would be expected. Consultancy companies, which are relatively simple in their business, tend not make adjustments and may not need to make adjustments. It is quite surprising that none of the paper and pulp companies made adjustments, although this is also a complex manufacturing activity that would seem to generate the need for adjustments. It is also surprising that four insurance, finance and investment companies did not make adjustments while seven of them did.

Table 3 Adjustment activity by industry

\begin{tabular}{|c|c|c|c|c|}
\hline \multirow[b]{2}{*}{ Industry } & \multicolumn{2}{|c|}{ Early 1990s survey } & \multicolumn{2}{|c|}{ Late $1990 s-2000$ survey } \\
\hline & $\begin{array}{c}\text { Made } \\
\text { adjustments }\end{array}$ & $\begin{array}{c}\text { No } \\
\text { adjustments }\end{array}$ & $\begin{array}{c}\text { Made } \\
\text { adjustments }\end{array}$ & $\begin{array}{c}\text { No } \\
\text { adjustments }\end{array}$ \\
\hline Manufacturing & 19 & 2 & 13 & - \\
\hline Transport & 3 & 2 & 2 & 1 \\
\hline Property and construction & 7 & 1 & 1 & 1 \\
\hline Paper and pulp & - & 3 & 2 & - \\
\hline Insurance, banking, investments & 7 & 4 & 5 & 3 \\
\hline Trading and commerce & 2 & 2 & 3 & 2 \\
\hline Consultancy & - & 5 & 2 & 4 \\
\hline Other & 3 & - & 4 & - \\
\hline Total & 41 & 19 & 32 & 11 \\
\hline
\end{tabular}




\subsubsection{Amount of foreign activity}

Yet another factor that may influence a company to make adjustments is the amount of its foreign activity. For this survey, we used a composite of number of employees and sales revenue to categorise foreign activity as major (greater than 50\%); medium (10-50\%); and minor (less than 10\%). The results, shown in Table 4, show that virtually all of the companies with major amounts of foreign business do make adjustments, as well as a bare majority of the companies with medium amounts of foreign business. The majority of those companies with small shares of foreign business do not make adjustments, a fact that might be attributed to materiality. The eight with medium or major foreign business that do not make adjustments are likely candidates for non-compliance.

Table 4 Adjustment activity by amount of foreign activity

\begin{tabular}{|c|c|c|c|c|}
\hline \multirow[b]{2}{*}{ Amount } & \multicolumn{2}{|c|}{ Early 1990s survey } & \multicolumn{2}{|c|}{ Late $1990 s-2000$ survey } \\
\hline & $\begin{array}{c}\text { Made } \\
\text { adjustments }\end{array}$ & $\begin{array}{c}\text { No } \\
\text { adjustments }\end{array}$ & $\begin{array}{c}\text { Made } \\
\text { adjustments }\end{array}$ & $\begin{array}{c}\text { No } \\
\text { adjustments }\end{array}$ \\
\hline Major* & $19(95 \%)$ & $1(5 \%)$ & $16(100 \%)$ & - \\
\hline Medium** & $12(63 \%)$ & $7(37 \%)$ & $9(65 \%)$ & $5(35 \%)$ \\
\hline Minor*** & $10(48 \%)$ & $11(52 \%)$ & $6(50 \%)$ & $6(50 \%)$ \\
\hline Total & $41(68 \%)$ & $19(32 \%)$ & $31(74 \%)$ & $11(26 \%)$ \\
\hline
\end{tabular}

Notes: * In the early 1990 s survey - more than $50 \%$ of sales are foreign or more than $50 \%$ of employees are foreign; in the late 1990s-2000 survey - more than 50 foreign subsidiaries ** In the early 1990 s survey -between 10 and $50 \%$ of sales are foreign or between 10 and $50 \%$ of employees are foreign; in the late 1990s-2000 survey - between 11 and 50 foreign subsidiaries

*** In the early 1990 s survey - less than $10 \%$ of sales are foreign or less than $10 \%$ of employees are foreign; in the late 1990s-2000 survey - less than 11 foreign subsidiaries One company did not respond to this item in the late 1990s-2000 survey

\subsubsection{Size of group}

The overall size of the company can also influence the adjustment activity of companies. Larger companies could be expected to have larger, more specialised accounting staff and financial managers with more accounting knowledge. We categorised companies as:

- large, if they had revenues of more than 10 billion Swedish crowns or more than 10,000 employees

- medium, if less than these amounts but more than 5 billion crowns revenue or 5000 employees

- small if less than these latter amounts.

The results in Table 5 show that a large majority of the large- and medium-sized companies did make adjustments, but six did not. The greatest number of companies not making adjustments, 13, were small companies, suggesting that small companies may not focus attention on consolidated financial reporting. 
Table 5 Adjustment activity by company size

\begin{tabular}{lccccc}
\hline & \multicolumn{2}{c}{ Early 1990s survey } & & \multicolumn{2}{c}{ Late 1990s-2000 survey } \\
\cline { 2 - 3 } Amount* & $\begin{array}{c}\text { Made } \\
\text { adjustments }\end{array}$ & $\begin{array}{c}\text { No } \\
\text { adjustments }\end{array}$ & & $\begin{array}{c}\text { Made } \\
\text { adjustments }\end{array}$ & $\begin{array}{c}\text { No } \\
\text { adjustments }\end{array}$ \\
\hline Large* $^{\text {Medium** }}$ & $15(83 \%)$ & $3(17 \%)$ & & $16(100 \%)$ & - \\
Small*** & $12(80 \%)$ & $3(20 \%)$ & & $8(80 \%)$ & $2(20 \%)$ \\
Total & $14(52 \%)$ & $13(48 \%)$ & & $8(47 \%)$ & $9(53 \%)$ \\
\hline
\end{tabular}

Notes: * Sales greater than 10 billion Swedish crowns or more than 10,000 employees

** Sales between 5 and 10 billion Swedish crowns or between 5000 and 10,000 employees

*** Sales less than 5 billion Swedish crowns or less than 5000 employees

\subsection{Late 1990s-2000 survey}

The survey was repeated to the same population in 1999, extending into 2000. Some individual companies in the population had changed, but all had the same characteristics as the earlier survey, i.e. Swedish multinationals with foreign subsidiaries. The survey was conducted some 10 years later to determine if there was a significant change in the adjustment activity of the companies. Companies had at least three years of experience with the new Swedish accounting legislation that was based on the true and fair view. In addition to the questions in the original questionnaire, more open-ended questions were added to the survey based on feedback received. The population comprised 76 companies, 91\% of the companies listed on the Stockholm Stock Exchange. Responses were received from 43 companies, a 57\% response rate. As shown in Table 1,74\% (31 companies) made vertical adjustments in order to conform to Swedish accounting standards. The types of adjustments made were essentially the same as those in the earlier survey, with the addition of adjustments for such items as amortisation of goodwill and other intangibles, write-down of assets and inflation accounting adjustments. In the latter survey, several companies commented on materiality being an issue in allowing some subsidiaries to deviate from Swedish accounting standards.

As in the earlier survey, auditors concurred that the financial reports followed Swedish accounting standards, despite the fact that some companies did not make adjustments and (as discussed below) accounting procedures for foreign currency translation appear to be problematic. As in the earlier survey, the influence of the auditor was perceived as the second most important factor in adjustment decisions, but our analysis of the specific auditing firms (not reported here to avoid disclosing names) did not reveal a pattern for specific firms.

\subsubsection{Disclosures}

At the time of the latter survey, Swedish accounting standards explicitly stated that "financial reports should use the uniform accounting principles of the parent company. If the consolidated group cannot comply with the principles of the parent company then non-compliance should be reported separately" (RR 1:96, item 8, emphasis added). 
A review of the annual reports of all 76 companies in the population showed the results reported in Table 6 . In the annual reports, the large majority of companies specifically stated that they did comply with accounting standards; none disclosed non-compliance with the standard that the uniform accounting principles of the parent company must be followed. A large majority made no disclosures of vertical adjustments. Yet, in the questionnaire survey, 11 companies stated they made no adjustments, a fact that should have been disclosed.

Table 6 Disclosures of vertical adjustments in annual reports in the late 1990s-2000 survey (results for all companies in population)

\begin{tabular}{lccc}
\hline & $\begin{array}{c}\text { Stated accounting } \\
\text { standards followed }\end{array}$ & $\begin{array}{c}\text { No reference to } \\
\text { accounting standards }\end{array}$ & Total \\
\hline Disclosed vertical adjustments & $11(17 \%)$ & $1(13 \%)$ & $12(16 \%)$ \\
No vertical adjustments disclosure & $57(83 \%)$ & $7(87 \%)$ & $64(84 \%)$ \\
Totals & $68(100 \%)$ & $8(100 \%)$ & $76(100 \%)$ \\
\hline
\end{tabular}

As in the earlier survey, we assessed various factors that may affect vertical adjustment activities of companies.

\subsubsection{Foreign currency translation}

Because of the experience in the earlier survey, in which most companies seemingly used an inappropriate translation method, we asked, directly, whether the method for foreign currency translation is important for making vertical adjustments. Only one company stated that the foreign currency translation method had some importance. Of the remaining 32 companies, three did not respond and 28 (88\%) responded that the foreign currency translation method was unimportant. We also asked whether the vertical adjustments were made before translation (i.e. in local currency) or after translation (i.e. in Swedish crowns). The large majority, $85 \%$ (27 companies) made adjustments in local currency. Only three companies reported they made adjustments in Swedish crowns; two did not answer. The companies made local currency adjustments even though it has been established that making adjustments in local currency will distort financial information, especially in countries with high inflation (e.g. see Choi, 1987). In the process of our analysis, we discovered that Eriksson (2001, p.19) surveyed the same population to determine the foreign currency translation method used. Again, a large majority, $82 \%$, used the current rate method even though it was clearly inappropriate in two situations that involved high inflation countries and questionable in others.

\subsubsection{Number of stock exchanges}

As shown in Table 2, a substantial number of companies (35\%, 11 companies), listed only on the Stockholm Stock Exchange, did not make adjustments. All 12 companies on two or more exchanges made adjustments. Of these, 10 were listed on one of the New York exchanges or the London Exchange, or both. 


\subsubsection{Industry group}

As shown in Table 3, the industry pattern of making adjustments is consistent with that of the earlier survey, although companies in some industries have shown a tendency to start making adjustments in the latter survey. Manufacturing companies, including paper and pulp, that did not make adjustments in the early 1990s, all now make adjustments. As earlier, consultancy companies tend not to make adjustments.

\subsubsection{Amount of foreign activity}

In the later survey, we changed the measurement of foreign activity to the number of foreign subsidiaries, based on feedback and analysis of earlier results. As shown in Table 4, in all categories, the portion of companies making adjustments had increased slightly since the early 1990s. The number of companies not making adjustments is still fairly large in the medium and small categories.

\subsubsection{Size of group}

The size of the companies was measured based on sales and number of employees as in the earlier survey. The results in Table 5 indicate that the number of companies not making adjustments have decreased in all categories since the earlier survey. Notably, all the larger companies make adjustments. Nonetheless, a substantial portion of the medium and smaller companies make no adjustments.

\section{Concluding discussion}

This study assesses major Swedish multinationals' compliance with Swedish accounting standards which state that consolidated statements should be prepared using the uniform accounting standards of the Swedish parent company. The focus is on vertical adjustments to the financial reports submitted from a foreign subsidiary to the Swedish parent company, because our analysis indicates that almost all adjustments occur vertically. Surveys were conducted on all Swedish multinational companies listed on the Stockholm Stock Exchange first in the early 1990s and again some ten years later in the late 1990s-2000. Among other things, we wanted to assess whether there was a substantial change in adjustment activity after a major change in Swedish accounting legislation in the mid-1990s.

The results show that foreign subsidiaries of most Swedish multinationals make vertical adjustments when information is sent to the parent company. They also show that the portion of companies making adjustments increased between the two surveys. A substantial number of companies, though, do not make vertical adjustments, although they claim that their statements conform to Swedish accounting standards and their auditors concur. In particular, at the time of the late 1990s-2000 survey, Swedish accounting standards required disclosure of non-compliance with the accounting standard requiring uniform accounting standards for consolidated financial reporting. None of the companies disclosed non-compliance in their annual reports, even though several companies responded to the survey that they did not make vertical adjustments. In all cases, the auditors concurred that the statements complied with Swedish accounting standards, although non-compliance with the standards on consolidation seemed highly 
likely. Moreover, although not the focus of the study, it became apparent that companies did not comply with prescribed accounting standards for foreign currency translation.

These results indicate that vertical adjustments are indeed an appropriate area of research interest, because vertical adjustments, or lack thereof, present opportunities for non-compliance that might go undetected. The results also give a strong indication that enforcement activity in Sweden is low with respect to both the companies preparing the financial reports and their auditors. Companies that were listed on London and New York stock exchanges, in countries where enforcement activity is well developed, consistently made vertical adjustments. The failure to make vertical adjustments per se, as reported by corporate headquarters, is not a proof of non-compliance with accounting standards. As a minimum, though, the results point to the need for additional research that examines the vertical adjustment activity of the subsidiaries themselves.

The results of the study obviously cannot be generalised outside of Sweden for this time period. They do suggest, however, that enforcement mechanisms for financial reporting and compliance with accounting standards could be major issues for the EU when the uniform use of international accounting standards based on the true and fair view become mandatory for publicly listed companies in 2005. The need for additional research in this area is indicated.

\section{References}

Choi, F.D.S. (1987) 'Resolving the inflation/foreign currency translation dilemma', Management International Review, Vol. 27, No. 2, pp.26-34.

Eriksson, L. (2001) 'Koncernredovisningspraxis 1999', ('Group accounting practice'), Working Paper, Luleå University, Sweden.

RR, Redovisningsgrådet (1996) Svenska Redovisningkommendationer (Swedish Accounting Standards), Stockholm.

Street, D.L. and Gray, S.J. (2002) 'Factors influencing the extent of corporate compliance with International Accounting Standards: summary of a research monograph', Journal of International Accounting Auditing and Taxation, Vol. 11, pp.51-76.

Street, D.L., Gray, S.J. and Bryant, S.M. (1999) 'Acceptance and observance of International Accounting Standards: an empirical study of companies claiming to comply with IASs', The International Journal of Accounting, Vol. 34, No. 1, pp.11-48.

\section{Notes}

1 International Financial Reporting Standards (IFRS) were previously called International Accounting Standards (IAS). This latter term and acronym are still widely used.

2 Copies of survey instruments, which are in Swedish, are available on request. 